\title{
Adaptive Learning in Psychology: Wayfinding in the Digital Age
}

\author{
Charles D. Dziuban, Patsy D. Moskal, Jeffrey Cassisi, and Alexis Fawcett \\ University of Central Florida
}

\begin{abstract}
This paper presents the results of a pilot study investigating the use of the Realizeit adaptive learning platform to deliver a fully online General Psychology course across two semesters. Through mutual cooperation, UCF and vendor (CCKF) researchers examined students' affective, behavioral, and cognitive reactions to the system. Student survey results indicated that students found the system easy to use and were generally positive about their seamless transition to adaptive learning. While the majority of students were successful, learning outcome metrics utilizing Realizeit indices indicated a potential for early prediction of students who are likely to be at risk in this environment. Recommendations are presented for the benefits of cooperative research between users and vendors.
\end{abstract}

\section{Background on Adaptiveness as a Learning Principle}

For the past several years, adaptive learning advocates have promoted its potential for transforming higher education. The concept, although considered by many a recent innovation, is anything but new. Even the most casual literature search will identify authors, professional organizations, industries, foundations, and government agencies advocating the importance of adaptiveness for learning (Bill and Melinda Gates Foundation, 2014; Levy, 2013; National DETA Research Center, 2014; Pacheco, 2014; Zmuda, Curtis, \& Ullman, 2015). Supporting this position, many authors have valued adaptiveness as a functional concept. For example, Illich (1972) broached the issue in his chapter on learning webs where he pondered who could be served by bridges to nowhere, suggesting adaptiveness by using educational objects, skill exchanges, peer matching and professional masters. Certainly, these constructs have clear analogs in our technologyenhanced, educational culture. Johnson (2010) reinforced Illich's (1972) learning web notion by describing the adjacent possible (that which is reasonably accomplished next) and liquid networks that feature feedback loops through idea exchange and refinement. Bates (1989) incorporated adaptiveness into her 
berrypicking model for information search where a particular discovery opens multiple pathways to information sources. In her framework, uniquely individual approaches to information and learning are not only possible but highly likely. Hall (2004) argued that in actuality, adaptive learning geographies signify a reorienting process where students not only gain knowledge but improve their learning processes incrementally. Morville (2005) termed that concept wayfinding and Turchi (2009) suggested that the most appropriate framing metaphor for adaptiveness is mapmaking as a version of learning cartography.

Other scholars approached the concept from even broader perspectives. Silver (2012) addressed the notion of progressive learning ability by using athletics, arguing that the path to significant achievement is rarely linear even for the most talented. According to him, rigidity impedes progress, while effective adaptive learning is best defined as controlled intensity. In a different framework, boyd (2014) argued that adaptability is critical to social networks because users must understand the interplay of context, audience, and identity in order to navigate virtual communities effectively-a seemingly important implication for learning networks. Shultz (2010) discussed the necessity of understanding that being wrong is a critical component in the learning process. She cited the writer Menand as saying, "...The right answer is, in a sense, a function of the mistakes" (p. 34)—suggesting that incorrectness increases the likelihood of following alternative paths. Levitt and Dubner (2014) were adamant in arguing that adaptiveness is the key to effective education, "The key to learning is feedback. It is nearly impossible to learning anything without it” (p. 34). Diamond (1997) further reinforced the adaptive feedback principle by characterizing the process as autocatalytic with continuous feedback loops, creating a sustaining synergy — an implicit reference to the go-at-your-own-pace capability of adaptive learning. Finally, Carpman and Grant (2012) provided a functional hierarchy for personal geographies (or adaptive learning) by what they identified as a directional sense. We augment their terms within the framework of learning:

- Know where you are (baseline measures)

- Know your destination (desired outcomes)

- Follow the best route (learning path)

- Recognize your destination (knowledge state)

- Find your way back (repeat, revise and reassess)

Adaptive learning is a critical component of many disciplines ranging from information search to forecasting and cultural evolution. However, no matter how diverse the disciplines are, there is apparent consensus about the core elements of adaptiveness: incremental learning, continual feedback, regular assessment, benchmarking, indexing growth and the availability of many paths to a final destination - the interaction of which alters the educational environment from a fixed setting to a flexible (adaptive) context.

\section{The Fundamental Premise of Adaptive Learning}

Like so many innovations in education and the social sciences, adaptive learning resonates with Senge and Roth's (1999) mental model and Bowker's and Star's (2000) boundary object concepts. Both theories underscore the difficulty of forming a precise definition for the adaptive process. According to Senge and Roth, mental models are conceptual frameworks of generalizations by which we organize our thinking (1999). According to Bowker and Star, boundary objects have functional definitions in individual constituencies but become much weaker in the general community of practice (2000). Most of us understand that the fundamental objective of adaptive learning is to provide greater flexibility and multiple paths to achievement with reduced time constraints, but precisely how that happens for students is more difficult to specify.

Adaptiveness in learning and assessment has been the topic of interest since the measurement pioneers such as Lord and Novick (2008), Rasch (1998), and Lazarsfeld (1995) began developing the theory and mathematics for adaptive testing, typically referred to as item response theory (IRT) (de Ayala, 2009; 
DeMars, 2010). Their work demonstrated that item difficulty and individual ability levels can be equated and placed on the same logarithmically anchored scale, thereby freeing educators from classical measurement theory that requires examinees to respond to every item on the test. In practice, an IRT examination presents an examinee with an initial item scaled with 1 to 3 parameters, and depending on whether or not they respond correctly, selects another item in progressing or decreasing difficulty. The process continues until there is assurance that the examinee's knowledge has been accurately determined. Because items and ability have been equated, there is no requirement in IRT that examinees be presented with exactly the same items or even an equivalent number of items. Currently, several national examinations, such as the nursing NCLEX certification (National Council of State Boards of Nursing [NCSBN], 2016), are administered using IRT, where one examinee may pass or fail with as few as 75 items presented, and another candidate may have to respond to 200 or more prompts before an accurate assessment of their knowledge level is achieved. Although this explanation is over-simplified, adaptiveness is well established and fully functional in the measurement domain-predominately apprising item characteristics.

In a parallel development, Carroll (1963) addressed adaptiveness from a learning perspective. In doing so, he laid out the basic equation necessary for learning to be truly adaptive. His theory suggests the following:

$$
\text { Degree of learning }=\mathrm{f}\left(\frac{\text { time actually spent }}{\text { time needed }}\right)
$$

The numerator in this formula is not elapsed time, but rather time actually spent on the learning process. The basic formula specifies that in order for a student to learn (or achieve a competency) he or she should have the time required to acquire mastery. This is the index for what has become an educational cliché. If how much time a student spends learning is a constant, then achievement will be the variable. If achievement is the constant, then how much time the student spends learning is the variable. Carroll contended that the numerator of the equation is moderated by perseverance and aptitude. He defined perseverance as a function of willingness to:

- Spend time beyond the ordinary,

- Withstand discomfort, and

- Tolerate failure.

With respect to aptitude, he argued that the construct is best understood in terms of time needed to achieve mastery. Therefore, less time indicates higher aptitude and more time equates to lower aptitude. However, Carroll was quick to point out that aptitude is moderated by several other factors, the most important of which is prior learning - a fundamental starting benchmark for most platforms that support the adaptive learning process. Carroll claimed that his model was less related to learning theory, and much more relevant to the economics of learning. However, in the contemporary adaptive learning process both elements play an important role. In order to be adaptive, one must embrace a theory of how students learn, embedded in an optimally efficient process.

The development of item response theory and Carroll's model have made significant contributions to adaptive learning as we have come to understand it. The measurement community has demonstrated that adaptiveness is not only possible but functionally efficient and highly effective. Carroll showed us that we can conceive the learning process as one that is much more responsive to where the student is, where he/she needs to be, how he/she learns best, the most efficient path to get there, and the most effective method by which to assess his/her progress. 


\section{History of Adaptive Learning Research}

The advent of faster computer technologies coupled with the ability to process large datasets has fueled a newfound interest in developing adaptive learning systems. In addition, the strong push to improve student learning outcomes, including retention in higher education has created an urgency to harness the potential of adaptive systems to address these perpetual problems to personalize instruction. Table 1 illustrates a variety of some (not all) adaptive learning systems developed at the time of this publication. Vendors and platforms provide a range of support and content. Content agnostic or open systems allow for more faculty or institutional control by providing the structure and logic of the adaptive shell but allowing for content to be developed by the institution--typically the faculty member, instructional designer or subject matter expert. Closed systems provide the advantage of off-the-shelf, previously developed courses that use the adaptive learning platform, but have minimal or no customization possible by faculty. These systems can provide a faster track to institutions utilizing adaptive learning because faculty are not encumbered by the significant time required to develop and personalize content. Often, these off-the shelf courses involve general education requirements or other offerings that may be similar in content across many higher education institutions (Brown, 2014; Tyton Partners, 2016). Perhaps in response to the additional time required to create or modify content, many vendors now provide instructional design support as well for those that provide significant authoring capabilities.

Much of the recent literature on adaptive learning has been focused on examining current adaptive learning platforms and the promise of adaptive learning's use for personalizing instruction (Brown, 2015; Tyton Partners, 2013, 2016). The definition of how truly adaptive a given software is varies widely, but generally the systems vary the path through the course material by student performance on assessments or student preference for a type of instruction. Approaches vary and adaptive algorithms are elusive for vendor products. Faculty may have limited ability to modify the adaptive course.

While there is promise of instructional improvements as a result of adaptive learning, little research has been done in this area. Currently, a number of funding possibilities is creating the potential for investigation into the use of adaptive learning in higher education (Bill and Melinda Gates Foundation, 2014; Association of Public \& Land-Grant Universities, 2016; Online Learning Consortium, 2016). Restrictions on the variety of adaptive approaches and campus climates makes comparison and generalizability of findings difficult, however. This article focuses on the use of the Realizeit adaptive learning platform to administer an online section of General Psychology at a large, metropolitan university (for more information on Realizeit, please see http://www.realize.it/).

\section{Adaptive Learning in the Realizeit System}

Realizeit incorporates probabilistic reasoning using Bayesian estimation procedures within an instructor-created learning network (Howlin \& Lynch, 2014; Silver, 2012). The Bayesian procedure utilizes students' initial baseline results to estimate their position in a curriculum framework. As learners progress through their adaptive courses, additional outcomes enable Realizeit to suggest alternative learning trajectories. This results in continuous updates of students' ability estimates, the knowledge they have acquired, those objectives that still require mastery and recommendations for optimal paths through the course material.

This design feature enables instructors to understand how learning components interact. Realizeit is capable of incorporating multiple learning resources into the curriculum such as video, audio, test, objective test questions, exercises and case studies, for example. 
Table 1. Examples of adaptive learning systems

\begin{tabular}{|c|c|}
\hline Resource Name & Content Source \\
\hline Acrobatiq & $\begin{array}{l}\text { Authoring platform with instructional design support with OER, faculty } \\
\text { designed or off-the-shelf, pre-loaded, publisher or Acrobatiq content }\end{array}$ \\
\hline ALEKS & Off-the shelf, not modifiable content \\
\hline Brightspace by D2L & $\begin{array}{l}\text { Authoring platform with instructional design support and content from OER, } \\
\text { publishers or Brightspace Learning Object Repository }\end{array}$ \\
\hline Carnegie Learning & Off-the-shelf courseware with minimal modifications possible \\
\hline Cerego & $\begin{array}{l}\text { Authoring platform and instructional design support with OER, real-time media, } \\
\text { standards-aligned content, lesson plans, learner-generated materials }\end{array}$ \\
\hline CogBooks & $\begin{array}{l}\text { Authoring platform and instructional design support for off-the shelf courseware } \\
\text { with content from OER, faculty, customers, publishers }\end{array}$ \\
\hline Difference Engine & $\begin{array}{l}\text { Authoring platform and instructional design service to customize course } \\
\text { offerings from OER, publisher, proprietary client content }\end{array}$ \\
\hline Drillster & $\begin{array}{l}\text { Authoring platform and instructional design service to customize course } \\
\text { offerings including publisher content }\end{array}$ \\
\hline Fishtree & $\begin{array}{l}\text { Authoring platform where faculty can create content and modes, standards- } \\
\text { aligned content, OER, real-time media, teacher lesson plans, premium publisher } \\
\text { content }\end{array}$ \\
\hline Flat World & $\begin{array}{l}\text { Off-the-shelf courseware with pre-loaded, modifiable content including Flat } \\
\text { World eBooks, OER, publisher content (VitalSource) }\end{array}$ \\
\hline $\begin{array}{l}\text { Fulcrum Labs } \\
\text { (formerly Adapt } \\
\text { Courseware) }\end{array}$ & $\begin{array}{l}\text { Off-the-shelf, pre-loaded, customizable courseware from subject matter experts, } \\
\text { peer reviewers }\end{array}$ \\
\hline Knewton & Platform with content from partners with limited customization \\
\hline LearnSmart & $\begin{array}{l}\text { McGraw Hill off-the-shelf courseware generated by subject matter experts based } \\
\text { on commercial texts. No customization by faculty }\end{array}$ \\
\hline LoudCloud Systems & $\begin{array}{l}\text { Authoring platform with customizable, standards-aligned, OER, real-time } \\
\text { media, lesson plans, premium publisher content }\end{array}$ \\
\hline Lumen Waymaker & $\begin{array}{l}\text { Off-the-shelf with pre-existing OER premium BBC video content modifiable by } \\
\text { faculty }\end{array}$ \\
\hline $\begin{array}{l}\text { Open Learning } \\
\text { Initiative }\end{array}$ & $\begin{array}{l}\text { Off-the-shelf courseware, preloaded with OER, pre-existing author materials, } \\
\text { external, pre-developed learning activities }\end{array}$ \\
\hline Realizeit & $\begin{array}{l}\text { Authoring and delivery platform with instructional design services incorporating } \\
\text { institution's content, OER, publisher content and various media }\end{array}$ \\
\hline Sherpath & Off-the-shelf, limited customizable content from Elsevier \\
\hline Smart Sparrow & $\begin{array}{l}\text { Platform and learning design service to design or import customizable content } \\
\text { from various sources. }\end{array}$ \\
\hline Snapwiz & $\begin{array}{l}\text { Adaptive and collaborative learning platform importing customizable content } \\
\text { from publishers, OER }\end{array}$ \\
\hline
\end{tabular}


Adaptability within the system bases itself on the following learning principles:

- A student's start position on an objective may be tailored by determining which concepts they have mastered.

- A learner's pathway through the curriculum--including revision and practice exercises-may be dynamically altered as they progress through the content based on learner behavior, attainment, performance, and progress. The system selects the most suitable content for students as they undertake a course module, given their learning requirement at that time.

- The system selects the most appropriate pedagogical elements (learning bits) within a concept or objective.

- Adaptations to learning paths are based on rules specified by the instructors or selections made by the students themselves.

Within Realizeit, the main source of adaptability originates from the intelligence engine discussed above; however, the instructor or the students may themselves personalize course content. Realizeit integrates with Learning Management Systems (LMS) such as Instructure Canvas to provide platformbased learning navigation. As students begin a class assignment in the LMS they are launched seamlessly into the equivalent Realizeit objective. The advantages of this process include single sign-on authentication, course and group synchronization, and automatic grade transfer to the LMS gradebook, including additional metrics and comments.

At almost every point in the learning process, the student has final control over learning and next steps within the system. They may alter their learning path progression (trying new concepts) and alternatively undertake review (revising/practicing previous concepts) procedures. In addition, they are able to view supplemental learning material including adding, removing, and reordering course elements within the content. However, this is not a completely open landscape for students but is structured for optimal learning while allowing for flexibility._Guidance is provided by the Realizeit system which directs students towards ability-appropriate activities to increase the potential for success. Additionally, instructors have the ability to modify learning objectives for students within their courses. This process can be facilitated with analytics data that improves interaction and intervention with students, ranging from asynchronous messages to real-time intervention.

\section{General Psychology in the Realizeit Adaptive Platform}

General Psychology is an introductory course, offered as one of the social foundations options required as part of the General Education Program (GEP) for undergraduates and also as part of the Psychology undergraduate curriculum. Because Psychology is the largest undergraduate major, resulting in substantial enrollment for the General Psychology course, the department chair (Dr. Jeff Cassisi) determined that adaptive learning might be a good fit for helping increase access, and improving learning outcomes for students choosing this class as part of their undergraduate program.

One section of PSY2012: General Psychology was redesigned by Dr. Jeff Cassisi to utilize the Realizeit adaptive learning platform. Online courses at UCF are delivered through the Instructure Canvas LMS, which UCF has branded Webcourses. Within Webcourses, UCF online courses typically follow a similar format, giving students a class "front door" that provides access to course announcements, gradebook, modules, discussions, syllabus, and any tools the instructor may utilize within the course. Webcourses email allows students to connect with instructor and students within a given course. All of this structure remained constant for the adaptive learning online course, so that students who were familiar with online courses at UCF would be familiar with the structure of this course as well. 
Psychology course content was divided into eight modules (history \& research, biology \& consciousness, human diversity \& development, sensation \& perception and learning, memory and thinking \& language, intelligence \& motivation, emotions \& health and personality, social psychology \& psychological disorders), each corresponding to approximately two chapters in the required course textbook. The link to each of these modules opened the Realizeit interface for students to engage with the adaptive content. When students completed a module, their assessment scores were then passed back to the Webcourses gradebook as one of the course module grades.

Overall course grades were comprised of the student grade in each of the eight modules (10\% each; $80 \%$ of total grade), an immersive research experience required of all General Psychology students (10\%), and a comprehensive, standardized (non-adaptive) final exam (10\%) that is administered in each General Psychology course. Criteria were set by the instructor within Realizeit and used by the system to calculate the grade passed back to the Webcourses gradebook for each module. Within the syllabus, students were given a schedule of suggested due dates to use as a guideline for managing their time in order to complete all modules by the end of the given 16-week semester session and prior to the final exam due date. Students were free to review the content within a given module to revise and improve their grade as many times as desired throughout the semester. Access to the modules closed the day before the last day of the final exam which was open to students for a one-week period.

\section{The Study: An Evolving Research Partnership}

This study assessed adaptive learning in General Psychology by assessing students' affective, behavioral, and cognitive involvement within Realizeit. Initially, the study evaluated student reaction to and satisfaction with learning in this modality, concentrating on positive and negative elements plus features that created ambivalence. Secondly, data were collected about how students interacted with the content, the instructor, and each other when they were free to traverse the course at their own pace. Subsequently, the investigators compared the performance of successful and unsuccessful students (gauged by a grade of C or better) on each of the eight course modules. These components of the research project were completed by the Research Initiative for Teaching Effectiveness (RITE) at the University of Central Florida (UCF) working with Dr. Jeff Cassisi, the instructor of record for the course.

In the contemporary educational environment the historic distinction between universities and vendors is beginning to blur just as the boundaries among disciplines and even colleges are much less rigidly defined. Certainly, both UCF and CCKF, the developer of Realizeit, have vested interests in adaptive learning but they have come to understand that cooperative research ventures strengthen both organizations. Further, both entities realize (no pun intended) that shared research and data advance both parties' understanding of how to implement adaptive learning in the most effective manner. The fundamental partnership premise for this study was that UCF and CCKF enter into a working agreement where data are shared, cross-analyzed, validated, presented, and published in an objective manner evaluating the adaptive learning process in the many contexts in which it is likely to appear. This study represents the first product of that partnership among UCF, the instructor, and CCKF - a new research protocol. In fact, this paper is a call for other vendors and universities to do the same so that the collaboration might be expanded. For us, this is valuable because UCF can do things CCKF cannot and CCKF can do things that UCF cannot. We need each other in order to progress most effectively and improve the research paradigm.

\section{The Data Collection Protocol}

Students' reaction to their adaptive learning experience was obtained through a questionnaire that was developed and validated by students, the instructor, and investigators from RITE. The initial version of the instrument was developed from a review of research on adaptive learning in higher education. From 
this review the investigators drafted a preliminary data collection protocol that captured student demographic information and addressed their perceptions with issues such as:

- Learning effectiveness

- Engagement and re-engagement with adaptive learning

- Learning personalization

- Seamlessness of the Realizeit platform

- Learning assessment accuracy

- Sequence effectiveness

- Guidance provided by the system

- Platform responsiveness

- General satisfaction with the system

The initial version of the instrument was revised according to the recommendations of faculty and CCKF researchers and pilot-tested with a group of students who had experience with learning in an adaptive system. Based on faculty and student recommendations, the final items were crafted and structured in a five-point Likert response format augmented with open-ended questions for more granular detail from students.

Achievement in each of the eight course modules was based on an assessment protocol developed by the instructor within Realizeit, producing a final score on each module for each student. These scores permitted comparison of the achievement levels of successful and unsuccessful students as the course progressed, documenting learning trends of those two groups.

In addition to outcome measures created by the instructor, the Realizeit system generates a large number of student performance analytics, internal to the system. Two of these indices were subjected to further analysis. The first outcome measure used in the study was an index created by Realizeit termed knowledge state. This denotes the average ability that students achieve in a module for which there is direct evidence (some assessment exercise) across all the nodes. For example, if there were 10 learning nodes for a particular module and a student achieved the maximum possible assessment score on each of them, their knowledge state score would be $100 \%$. Knowledge state in the Realizeit adaptive learning system is expressed as a ratio of achieved to possible accomplishment. The second was percentage of nodes covered by each student for the course modules. For instance, the module human diversity and development is comprised of a number of learning nodes that may be typified by readings, videos, quizzes, activities, case studies, assignments, postings, discussions, etc. If students complete all activities associated with a module within Realizeit, the system records $100 \%$ for percentage of nodes covered, thereby representing a surrogate for the degree to which students engaged in this module (and throughout the course).

\section{The Study Sample}

The sample for this study was comprised of students who registered for the fully online adaptive learning section of General Psychology in the fall 2014 or spring 2015 semester (n=292). Students selfselected the fully online course, but were not aware of the use of adaptive learning until the first week when the class opened. The syllabus described the use of the adaptive learning system, Realizeit, as well as grading procedures. Students provided responses to the questionnaire and were tracked for achievement in the course through instructor-developed assessment and engagement with Realizeit through system analytics. Student demographic survey responses indicated that on average they were 19 years old, 57\% female and $42 \%$ male, with academic class breakdown of freshmen (33\%), sophomores (29\%) juniors (21\%), and seniors (13\%). Thirty-one percent of respondents classified themselves as white/Caucasian, 
18\% Hispanic/Latino, 12\% Black/African American, 6\% Asian, and 30\% preferred not to disclose their ethnicity.

\section{Methodology}

Before assessment of the student responses to the questionnaire was completed, the psychometric quality (domain sampling) of the information yielded by the instrument was determined. The reliability was computed using coefficient alpha (Cronbach, 1951). Frequencies for each of the survey items were calculated and examined along with means and standard deviations for those who engaged with various features of Realizeit.

Kaiser and Rice (1974) developed a measure of sample adequacy (MSA) that provides evidence about whether or not the student responses produce an adequate psychometric sample that is a set of items that properly represents a domain of interest. The index is limited by 0 and 1 and if the value is in the .80 to .99 range, the investigator has evidence of a proper domain sample. Values in the .70s signal a generally acceptable result, and those in the .60s indicate data that are unacceptable. MSA has been used as a data assessment index before any factoring analyses are completed. This procedure is recommended by Dziuban and Shirkey (1974) prior to any latent dimension analysis and was used with the data obtained for this study.

These data provided baseline information for determining what degree of favorableness toward this learning mode might be expected. In addition, these responses were the identifying sources of potential problems and steps that need to be taken in order to improve the adaptive learning environment and support for students.

\section{Dimensionality of Student Responses}

The investigators sought to determine the underlying dimensionality of students' perceptions about their adaptive learning experience. This can be accomplished through the application of some variant of the factor analysis procedure. In this study the method used was maximum likelihood factor analysis (Muliak, 2009). This approaches has the advantage of producing pattern coefficients that are maximum likelihood estimators of population values. In addition to traditional methods for determining the number of common factors to extract, the procedure uses a goodness-of-fit statistical test as well.

The number of factors retained in the final solution was accomplished by using three procedures. The first two, goodness of fit and eigenvalues of the correlation matrix greater than one appear extensively in scientific literature (Mulaik, 2009). However, a third technique originally proposed by Dziuban and Shirkey (1993) and validated by Hill (2011) was incorporated into the process as well. The algorithm initiates with an initial assessment of the data set with the MSA followed by iterative MSA computation on the matrix of partial correlations remaining after each factor is removed. Once a value in the .60s is encountered, there are no more dimensions to be derived from the data. What remains is basically noise. Kaiser and Rice (1974) demonstrated that in addition to the overall MSA for a correlation matrix, individual MSA values can be computed for each item on the questionnaire. This provided the investigators with a final opportunity to screen their data and improve the domain sampling. The individual MSAs were computed for each item and those with values in the .60 range were removed-because in Kaiser's words they don't belong to the family psychometrically. This resulted in an increase in the overall MSA from .81 to .89. The initial pattern matrix was transformed (rotated) according to the promax procedure (Hendrickson \& White, 1964). Pattern coefficients absolutely larger than .30 were used for interpretation purposes.

Once the final dimensionality was completed, factor scores for each subject in the sample were derived using the Anderson and Rubin (1956) method. These scores have a mean of zero and a standard deviation of one and produce a reasonably good relationship to the estimated factor validity. The scores 
were then arbitrarily rescaled to have a mean of 50 and standard deviation of 10 for ease of interpretation (T-score transformation). Subsequently, the investigators used the question "Realizeit helped me learn" with the K-Means clustering procedure (Hartigan \& Wong, 1979) to identify noteworthy sub-groups in the sample that might respond differently at the latent trait level.

Module score means were tested for significant differences and effect sizes computed for the successful and unsuccessful students (Hedges, 1981). In addition, trend lines on the module means and standard deviations for those groups were constructed. Finally, the means and standard deviations for knowledge state and knowledge covered were compared for the top 20 and bottom 20 performing students and the class as a whole.

\section{Results}

\section{Student attitudes toward adaptive learning and the Realizeit platform}

Overall, students were positive about their experience with adaptive learning in the Realizeit platform. Table 2 illustrates the means (5=high; 1=low) and standard deviations for each question of the survey. Survey questions were selected to assess the usability of the Realizeit system-whether students found the system and its various functions and features easy to use, how well students felt the system captured their knowledge through the difficulty of items and pathways presented to them, and the student perceptions of Realizeit's ability to help them learn and remain engaged. In addition to demographics, students were asked their overall satisfaction with the system and its components-whether it became personalized to them, if they followed system recommendations, their perception of time spent in the system, and finally, whether they would take another class using Realizeit if given a choice.

In terms of system usability, the majority of students felt the system was easy to use, as were the learning path and guidance panel features, with clear instructions provided. While over half of the students indicated they felt the guidance panel was helpful and easy to use, 23\% indicated they did not use this feature or did not know what it was. Seventy-seven percent of the class indicated that they felt Realizeit provided them with the feedback necessary to stay on track.

Students (74\%) believed the system accurately assessed their ability levels in psychology and that the grades accurately reflected their ability. Three-fourths of the class felt that the system increased their engagement with the course content over traditional instructional methods.

In rating the difficulty levels, the majority of students felt the difficulty levels of the learning path sequence (45\%), material (46\%), and questions asked (47\%) were neither easy nor hard. Few found each to be somewhat or too difficult (13\%; 16\%; $28 \%$, respectively).

The system provides students with suggested "next steps" although students can choose to ignore that suggestion. Survey respondents indicated that over half of students (53\%) always or quite often followed the system recommendation while $28 \%$ sometimes did and $18 \%$ rarely or never followed these system suggestions. Nearly half of the students (47\%) felt they spent more time in Realizeit compared to other formats, while 54\% indicated they felt they spent an equivalent amount of time or less than in a nonadaptive format. Many of the students (64\%) reported that the system became personalized to them over time. And, $78 \%$ of students indicated that they would take another course using Realizeit if given a choice.

As is often the experience when utilizing a platform (or any instructional technique) for the first time, there were minor system issues that were resolved as the semester progressed. As such, the investigators queried students about whether these "glitches" impacted them in any appreciable manner. However, 92\% of those surveyed indicated that they did not experience any technical issues with the system. Only $1 \%$ of students $(n=3)$ had issues they felt were not adequately resolved. 
Table 2. Student reactions to survey items

\begin{tabular}{lrrr}
\hline Item & $\mathrm{n}^{*}$ & $\overline{\mathrm{x}}$ & $\mathrm{SD}$ \\
\hline Realizeit helped me learn the course material & 241 & 4.02 & .92 \\
Realizeit's assessment exercises were effective & 235 & 3.82 & .78 \\
Difficulty of the "learning path" sequence & 240 & 3.35 & .81 \\
Difficulty of the learning material & 241 & 3.24 & .78 \\
Difficulty of the questions asked & 239 & 2.99 & .80 \\
Realizeit increased my engagement & 233 & 3.92 & .87 \\
Grading accurately reflected my knowledge & 229 & 3.81 & .86 \\
Ability levels reported by Realizeit were accurate & 235 & 3.79 & .84 \\
I would take another course using Realizeit & 234 & 4.09 & .99 \\
Realizeit system became personalized to me & 228 & 3.67 & .87 \\
I followed recommended "next steps” & 239 & 3.51 & 1.11 \\
Time spent in Realizeit & 229 & 3.31 & 1.15 \\
Realizeit was easy for me to use & 234 & 4.24 & .77 \\
The instructions in Realizeit were clear & 241 & 4.12 & .80 \\
"Learning Path" was easy to use & 184 & 4.01 & 1.00 \\
"Guidance panel” was easy to use & 211 & 3.91 & .89 \\
Realizeit provided me with the necessary feedback & 237 & 3.86 & .78 \\
"Guidance panel” was helpful & 182 & 3.81 & .67 \\
\hline
\end{tabular}

*differing n’s represent missing data

\section{Factor Results}

The promax transformed pattern matrix for the maximum likelihood analysis of student responses to the Likert scale items regarding the Realizeit adaptive platform is presented in Table 3 . All three methods for determining the number of common factors converged on three dimensions. The goodness of fit probability was .26 and three eigenvalues were greater than one. The residual MSA after extracting three factors was .54. Individual MSAs ranged from .70 to .92. The alpha reliability coefficient was .89 and the variables exhibited virtually no complexity indicating an acceptable solution. 
Table 3. Promax Transformed Pattern Matrix - Maximum Likelihood Factor Analysis (n=244)

\begin{tabular}{|c|c|c|c|c|}
\hline Ittom & \multicolumn{3}{|c|}{ Component } & \multirow{2}{*}{ MSA } \\
\hline Item & 1 & 2 & 3 & \\
\hline Realizeit helped me learn the course material & .72 & -.24 & .03 & .71 \\
\hline I would take another course using Realizeit & .71 & -.06 & -.03 & .73 \\
\hline Ability levels reported by Realizeit were accurate & .68 & .05 & -.11 & .70 \\
\hline Realizeit increased my engagement & .68 & -.06 & .00 & .76 \\
\hline Realizeit provided me with the necessary feedback & .65 & .08 & .08 & .77 \\
\hline The instructions in Realizeit were clear & .64 & .03 & .02 & .92 \\
\hline Realizeit's assessment exercises were effective & .59 & .21 & -.09 & .89 \\
\hline The grading accurately reflected my knowledge & .52 & .23 & -.11 & .92 \\
\hline The Realizeit system became personalized to me & .51 & .08 & .07 & .91 \\
\hline Realizeit was easy for me to use & .50 & -.01 & .22 & .87 \\
\hline The difficulty of the learning material & .04 & .71 & -.01 & .89 \\
\hline The difficulty of the sequence & -.01 & .56 & .16 & .89 \\
\hline The difficulty of the questions asked & -.01 & .52 & -.03 & .89 \\
\hline "Guidance panel” effective & .00 & .03 & .63 & .89 \\
\hline "Learning Path" effective & -.01 & .05 & .56 & .90 \\
\hline Eigenvalues & 4.7 & 1.9 & 1.3 & \\
\hline \multicolumn{5}{|l|}{$\chi^{2}=69.7 \mathrm{p}=.26$} \\
\hline \multirow[t]{2}{*}{ Factor Correlations } & .15 & & & \\
\hline & .39 & .19 & & \\
\hline \multicolumn{5}{|l|}{ Overall MSA $=.86$} \\
\hline \multicolumn{5}{|l|}{ Residual MSA $=.54$} \\
\hline \multicolumn{5}{|l|}{ Alpha $=.89$} \\
\hline \multicolumn{5}{|l|}{ Components: } \\
\hline \multicolumn{5}{|l|}{$1=$ adaptive effectiveness } \\
\hline \multicolumn{5}{|l|}{$2=$ course noise } \\
\hline 3 = Realizeit guidance & & & & \\
\hline
\end{tabular}

The first factor named adaptive effectiveness indicated that students in this environment evaluate their course with a dimension that reflects their judgment about whether adaptive learning represents a viable course modality. By evaluating the Realizeit platform, students responded to adaptive learning by how well it facilitates their learning, engages them, assesses their progress and clearly specifies the rules of engagement. The second factor represented a dimension named course noise that relates to the degree to which students encounter interference in the learning process emanating from the course model and underlying technology. In a sense this is the did adaptive learning get in the way factor. The final dimension, Realizeit guidance, indexes the core value of adaptive learning because students judged Realizeit by how effectively the system's guidance algorithms helped them learn the material and acquire the concepts of general psychology. The factor correlations range from .39 to .15 indicating a general independence with the strongest relationship found between effectiveness and guidance.

\section{Factor Score Analysis}

The means, standard deviations, significance levels and effect sizes on the rescaled factor scores for the two student clusters based on the "Realizeit helped me learn" item are presented in Table 4. Graphical portrayal of that relationship is presented in Figure 1. Based on those results the two groups responded differently about adaptiveness being an effective learning climate ( $p=.00, E S=2.28)$. Cluster one appears strongly positive while cluster two is somewhat more ambivalent toward this approach. The number of students in the positive group was greater than three times the number in the ambivalent group, indicating 
that the large majority viewed adaptive learning as an effective learning device. The ambivalent group, however, saw significantly more course noise $(\mathrm{p}=.01, \mathrm{ES}=.38)$ and found the guidance feature of Realizeit significantly less helpful ( $\mathrm{p}=.03$, ES=.36). From these results there appears to be an interaction among factors about how students respond to adaptive learning. The variability for the effective climate factor scores for the two groups was significantly different for the groups $(\mathrm{p}=.00)$. The groups were not significant on variability for noise and guidance ( $\mathrm{p}=.14$ and $\mathrm{p}=.82)$.

Table 4. Comparison of cluster factor scores for adaptive effectiveness, course noise, and Realizeit guidance.

\begin{tabular}{llccrcccc}
\hline & & $\mathrm{n}$ & $\overline{\mathrm{x}}$ & \multicolumn{1}{c}{$\mathrm{SD}$} & $\mathrm{p}$ & HVP & ADJP & ES \\
\hline \multirow{2}{*}{ Adaptive effectiveness } & Cluster 1 & 188 & 52.9 & 7.5 & .00 & .00 & .00 & 2.28 \\
& Cluster 2 & 54 & 39.8 & 10.8 & & & & \\
\multirow{2}{*}{ Course noise } & Cluster 1 & 188 & 49.1 & 9.4 & .01 & .14 & .03 & .38 \\
& Cluster 2 & 54 & 52.9 & 11.5 & & & & \\
\multirow{2}{*}{ Realizeit guidance } & Cluster 1 & 188 & 50.7 & 9.9 & .03 & .82 & .03 & \\
& Cluster 2 & 54 & 47.2 & 10.2 & & & & \\
\hline
\end{tabular}

Cluster 1 = positive

Cluster 2 = ambivalent

HVP = variance homogeneity

ADJP = Welch adjusted probability

ES = Hedges' g

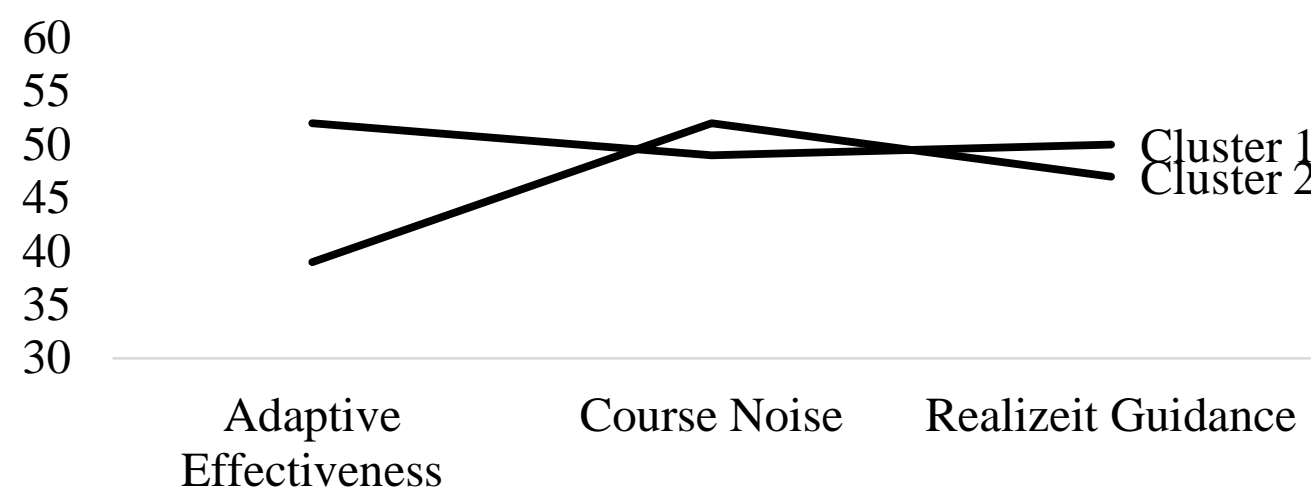

Figure 1. Factor score means comparison based on K-means cluster of Realizeit helped me learn

\section{Module Scores for Successful and Unsuccessful Students}

Table 5 presents some noteworthy results showing that after the first module in the class (History \& Research) there was a rapid divergence of the success and nonsuccess groups' achievement. This module showed a difference of 9.3 compared to $9.0(p=.05$, ES=.43). In addition, for Module 1 the variances in the groups showed no significant difference $(\mathrm{p}=.17)$. This module covered the basic "introductory" information. However, after that module, the drop-off for the non-successful group was pronounced and rapid. All mean differences were significant, as were differences in the variability of the groups. For Module 8 (Social Psychology \& Psychological Disorders) the mean differences were 9.1 compared to 1.2 ( $\mathrm{p}=.00$ ) with a large effect size (ES=5.13). In fact, the difference in performance on Module 2 (Biology \& Consciousness) for the two groups (9.5 compared to 7.4, $\mathrm{p}=.00$ ) is an effective predictor for who will succeed and who will not if no further intervention is initiated. These findings suggest that there may be an 
analytics component embedded in adaptive learning. Figures 2 and 3 portray the important findings graphically. Figure 2 demonstrates the early and rapid achievement decline of non-successful students. Figure 3 demonstrates an equally noteworthy finding. After Module 1, the variability in performance of non-successful students is large compared to those who succeed. Non-successful students are considerably different from each other in the way they approach learning.

Table 5. Comparison across Realizeit module scores for successful and unsuccessful students

\begin{tabular}{|c|c|c|c|c|c|c|c|c|}
\hline Module & & $\mathrm{n}$ & $\overline{\mathrm{x}}$ & SD & $\mathrm{p}$ & HVP & ADJP & ES \\
\hline \multirow{2}{*}{ 1: History \& Research } & Success & 278 & 9.3 & .67 & .05 & .20 & .17 & 0.43 \\
\hline & Non-success & 14 & 9.0 & .94 & & & & \\
\hline \multirow{2}{*}{ 2: Biology \& Consciousness } & Success & 278 & 9.5 & .40 & .00 & .00 & .00 & 2.42 \\
\hline & Non-success & 14 & 7.4 & 3.3 & & & & \\
\hline \multirow{2}{*}{$\begin{array}{l}\text { 3: Human Diversity \& } \\
\text { Development }\end{array}$} & Success & 278 & 9.4 & .61 & .00 & .00 & .00 & 2.61 \\
\hline & Non-success & 14 & 6.5 & 4.7 & & & & \\
\hline \multirow{2}{*}{$\begin{array}{l}\text { 4: Sensation \& Perception } \\
\text { and Learning }\end{array}$} & Success & 278 & 9.4 & .42 & .00 & .00 & .00 & 3.04 \\
\hline & Non-success & 14 & 6.1 & 4.2 & & & & \\
\hline \multirow{2}{*}{$\begin{array}{l}\text { 5: Memory and Thinking \& } \\
\text { Language }\end{array}$} & Success & 278 & 9.4 & .69 & .00 & .00 & .00 & 3.47 \\
\hline & Non-success & 14 & 5.4 & 4.4 & & & & \\
\hline \multirow{2}{*}{$\begin{array}{l}\text { 6: Intelligence and } \\
\text { Motivation }\end{array}$} & Success & 278 & 9.4 & .75 & .00 & .00 & .00 & 4.20 \\
\hline & Non-success & 14 & 4.5 & 4.1 & & & & \\
\hline \multirow{2}{*}{$\begin{array}{l}\text { 7: Emotion \& Health and } \\
\text { Personality }\end{array}$} & Success & 278 & 9.3 & .53 & .00 & .00 & .00 & 6.41 \\
\hline & Non-success & 14 & 2.8 & 3.4 & & & & \\
\hline \multirow{2}{*}{$\begin{array}{l}\text { 8: Social Psychology \& } \\
\text { Psychological Disorders }\end{array}$} & Success & 278 & 9.1 & 1.4 & .00 & .00 & .00 & 5.13 \\
\hline & Non-success & 14 & 1.2 & 3.3 & & & & \\
\hline
\end{tabular}

HVP = variance homogeneity

ADJP $=$ Welch adjusted significance

ES = Hedges’ g

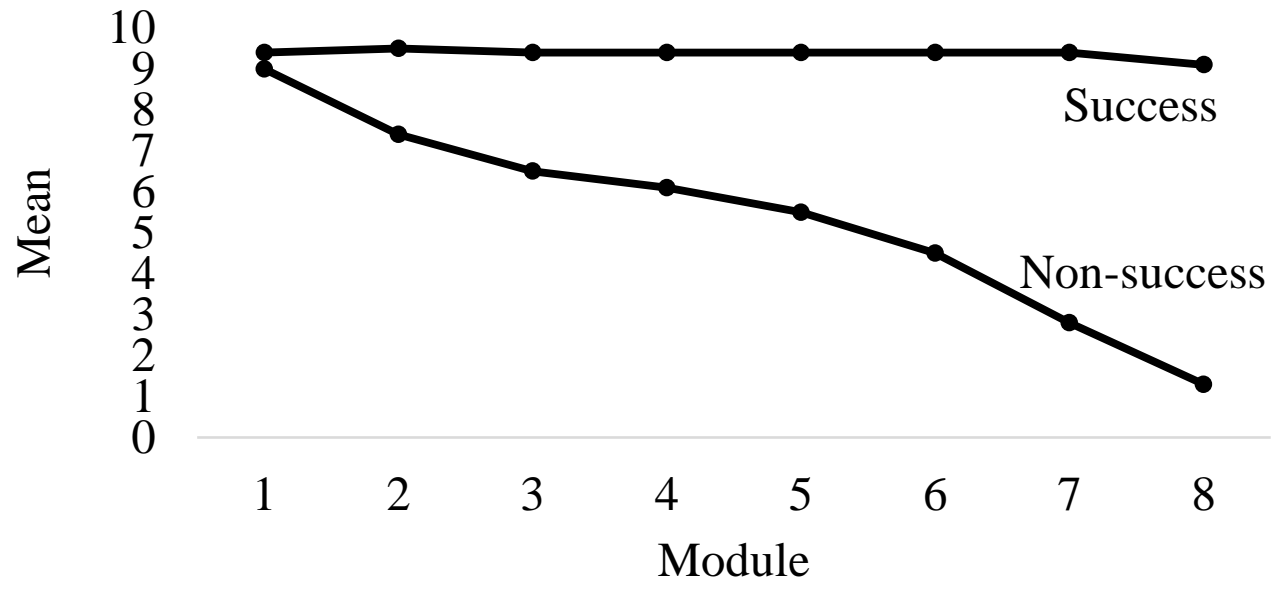

Figure 2. Module mean scores for successful and unsuccessful students 


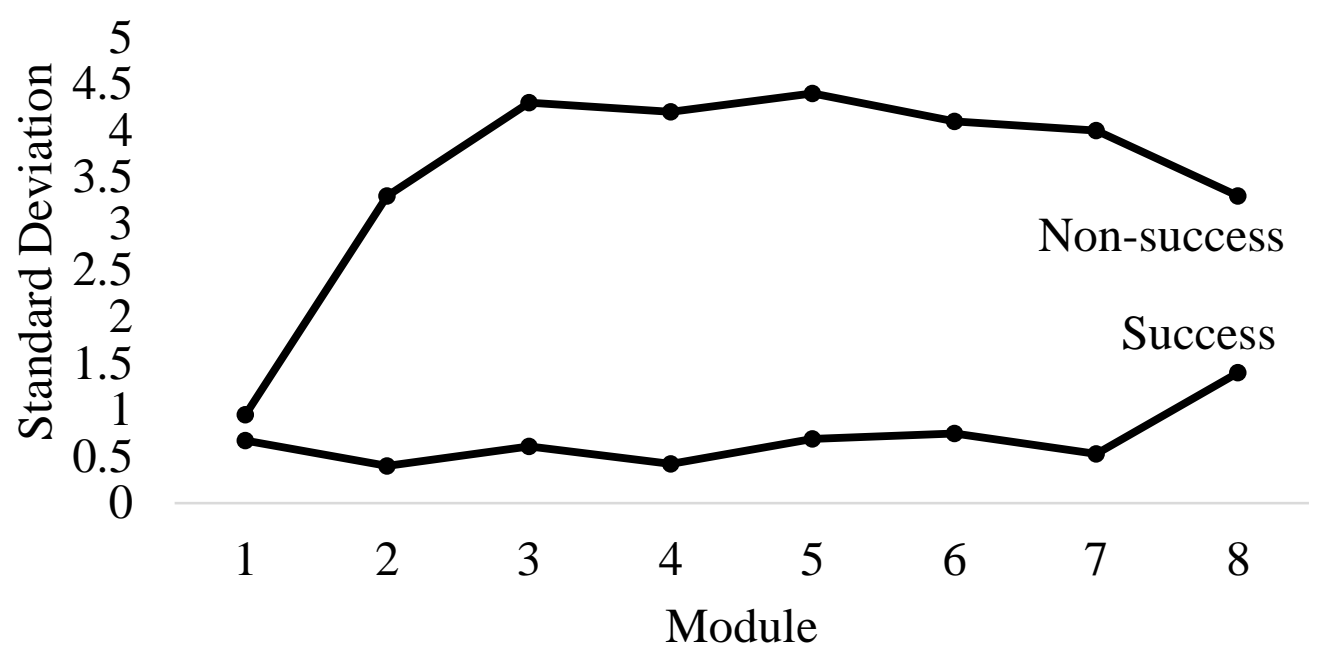

Figure 3. Module standard deviations for successful and unsuccessful students

\section{CCKF Analysis}

All results presented to this point were generated by RITE working with the course instructor. However, in the study section of this article the authors indicated that this research project was cooperative venture between RITE, the psychology instructor and the research unit of CCKF, the developers of Realizeit (chief research scientist, Colm Howlin). CCKF identified the top and bottom 20 students in the classes across all achievement measures in the platform and compared them with the class as a whole on the two measures (knowledge state and knowledge covered) for each of the eight modules. Clearly, there are dependences in these data since the top and bottom 20 students are included in the overall class data, thereby precluding any meaningful significance testing that requires independence. However, from a descriptive perspective Table 6 and Figures 4 and 5 present useful information. Table 6 shows that the percentage scores for the top and bottom students are 95.6 and 58.8, respectively while the average for the class is 89.4. This shows that there is an approximate $37 \%$ achievement differential between the top and bottom groups, a $31 \%$ difference between the class and the bottom group, with only a $6 \%$ difference between the top twenty students and the class in general. This is an interesting finding discovered by CCKF. Figure 4 demonstrates that the knowledge state profiles for the top 20 students and the class are approximately the same shape, close to each other, and virtually at the same level. However, the bottom twenty show marked dissimilarity on all three of those profile characteristics, suggesting that there are distinctly different groups in the adaptive learning environment. In addition, there is a large standard deviation in the lower group compared to the top twenty and the class (18.1 compared to 1.2 and 1.6, respectively).

Table 6. Comparison of knowledge state percentage and knowledge covered percentage across modules for the top and bottom 20 students with the class as a whole*

\begin{tabular}{llcc}
\hline & & $\overline{\mathrm{x}}$ & SD \\
\hline \multirow{3}{*}{ Knowledge state } & Top 20 & 95.6 & 1.2 \\
& Class & 89.4 & 1.6 \\
& Bottom 20 & 58.8 & 18.1 \\
& Top 20 & & \\
\multirow{2}{*}{ Knowledge covered } & Class & 99.9 & .07 \\
& Bottom 20 & 94.7 & 2.4 \\
& & 58.8 & 21.4 \\
\hline
\end{tabular}

* Completed by Colm Howlin, chief research scientist, CCKF 

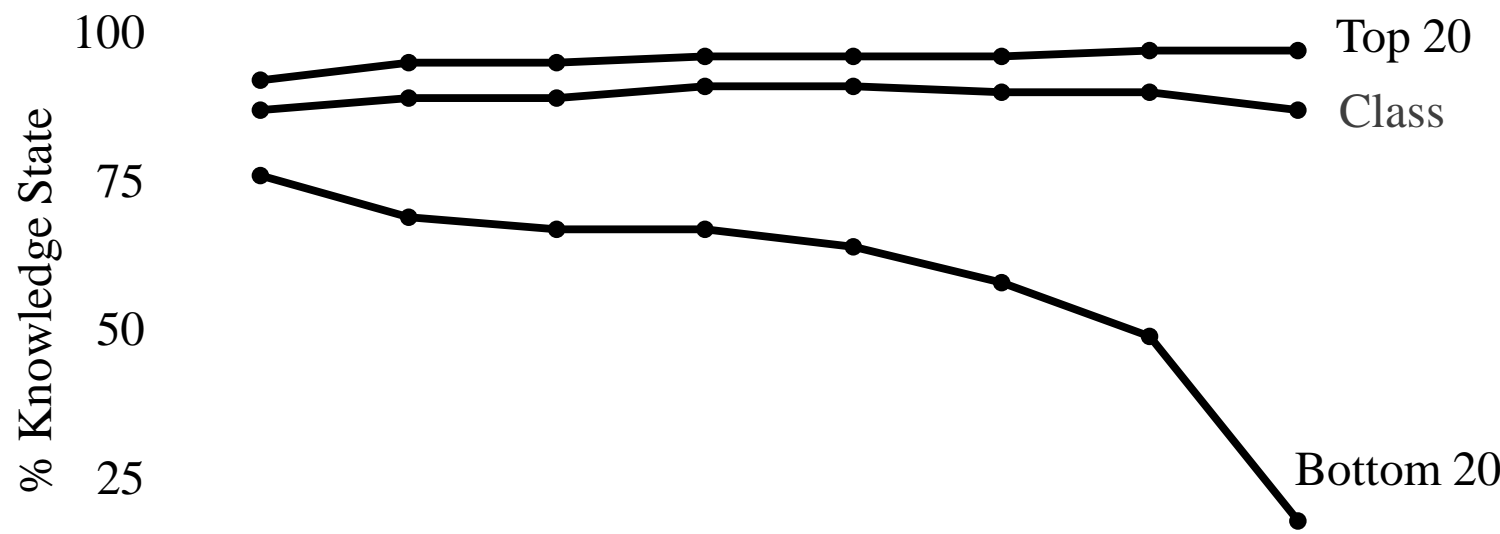

0

$\begin{array}{llllllll}1 & 2 & 3 & 4 & 5 & 6 & 7 & 8 \\ \text { Module } & & \end{array}$

Figure 4. Knowledge state percentage across modules for the top and bottom 20 students compared to the entire class. (Completed by Colm Howlin, chief research scientist, CCKF).

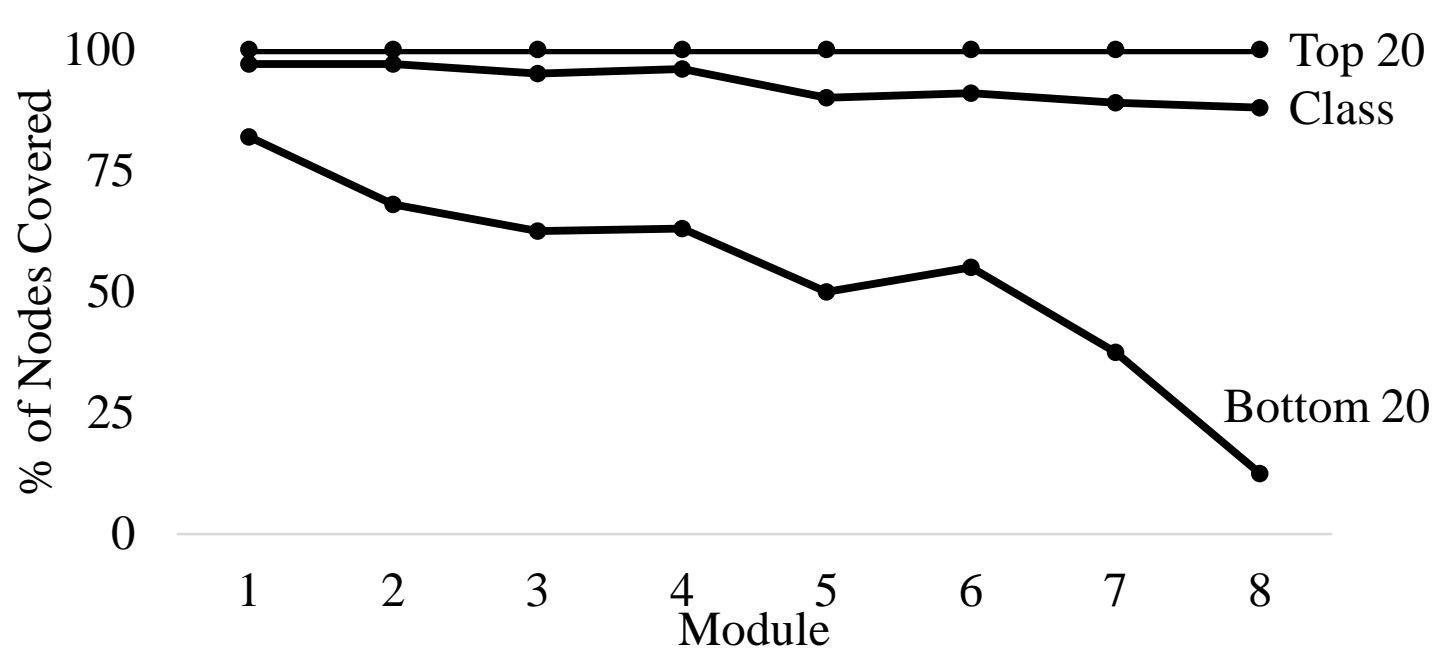

Figure 5. Knowledge covered percentage across modules top and bottom 20 compared to the entire class. (Completed by Colm Howlin, chief research scientist, CCKF).

Table 6 for knowledge covered shows a very similar trend. This variable indicates the percentage of nodes completed across the eight modules. One may observe from the table that the top twenty students completed virtually all of the modules (99.9\%). Simply stated, they did all the work. The class in general 
was not far behind completing $94.7 \%$ of the nodes for the course. The bottom group, however, completed approximately $59 \%$ of the work available in the course- $40 \%$ less than the top group and $36 \%$ less than the class in general. The standard deviation for knowledge covered shows a pattern similar to knowledge state. The top 20 and the class are close (.07 and 2.4), although to some extent this is an artifact since there is virtually no variability in the top group. The bottom twenty students exhibit much more variance in their behavior ( $S D=21.4)$. Figure 5 demonstrates a profile pattern for knowledge covered very similar to the one for knowledge state (Figure 4). The top 20 students and the overall class are very similar while the bottom group demonstrates noteworthy and a different course engagement pattern. Both of these findings created by CCKF reinforce those found by RITE for the module scores. Early in the course, the adaptive learning environment offers the potential for identifying future at-risk students by considering their engagement patterns.

\section{Limitations}

There are several limitations associated with this study that impact the methods, data analysis, results, and conclusions. Most important is that although hypothesis tests were completed throughout the data analysis, the findings should be considered primarily descriptive. Because the students self-selected into the classes, randomization was not possible and many of the assumptions associated with these tests were not accommodated. Therefore, the probability levels reported should be interpreted with caution, although the authors contend that the procedures used for data analysis are relatively robust with the exception of random assignment.

A second limitation arises from the fact that although this study was conducted over two semesters it lacks a longitudinal component. This study failed to address the overriding long-term impact of adaptive learning in the study of psychology. In addition, this work took place in an introductory class and did not address the implications for more advanced topics that involve hierarchical structures, such as industrial/organizational psychology, statistics, or clinical courses, for instance. Although the eight modules of the course have an imposed sequence, they are relatively independent of each other. Therefore, they may not capitalize on the topic prerequisite dependencies assumed in adaptive platforms.

In addition, the self-report aspect of student responses to this learning modality leave some unanswered validity questions. Traditional Likert scales force students into approximate categories that ignore the within-group variability. There was no way to address that issue in this study so that the ratio of between to within variance was ignored by using measures of central tendency or reporting individual category responses. Although great care was taken to establish proper domain sampling, the factor analytic work here was completed on individual items with their presumed low reliability. Once again this limits the generalizability of these findings.

Finally, the pedagogy and technology involved in adaptive learning is continually changing. The interplay between the instructor and the developers of Realizeit resulted in platform and course modifications throughout the semester, creating slightly nuanced versions of adaptive learning experienced by the students. At the moment this modality is in a continual state of flux so that although this study may appear to be focused, baseline work is more directly a boundary object relating to the complexity of adaptive learning.

\section{Discussion}

Adaptive learning presents opportunities and creates challenges for higher education. The fundamental nature of these adaptive systems allows students to immerse themselves in content and progress through the material at their own pace-in theory, as quickly or as slowly as an instructor-defined course structure allows. However, this creates the possibility of an isolated environment for students who interact primarily with the system and infrequently with each other. In examining this question, the survey 
results indicated that students perceived themselves as interacting less or much less (75\%) with each other than in a course not using Realizeit (Table 7). However, the researchers wondered how much students wanted to interact with each other in the classroom. Only $20 \%$ of them preferred some or substantial interaction with other students; $29 \%$ had no preference; and $52 \%$ of those responding indicated that they preferred little or no interaction with other students in their classes (Table 8). When indicating their preferred method of interacting, the majority of students (59\%) indicated discussion boards-possibly because this is the predominate method used within the online instructional environment and therefore the one with which they are most familiar (Table 9).

Table 7. Frequency of perceived interaction with other students compared to non-adaptive class.

\begin{tabular}{lr}
\hline Response & $\%$ \\
\hline Much less & 51.3 \\
Less & 23.9 \\
About the same & 18.5 \\
More & 4.2 \\
Much more & 2.1 \\
\hline
\end{tabular}

Table 8. Preferred frequency of interaction of students in class.

\begin{tabular}{lr}
\hline Response & $\%$ \\
\hline None & 22.1 \\
A little & 29.6 \\
No preference & 28.7 \\
Some & 17.1 \\
A lot & 2.5 \\
\hline
\end{tabular}

Table 9. Preferred method of interaction for students.

\begin{tabular}{lr}
\hline Method & $\%$ \\
\hline Discussion boards & 59.4 \\
Live chat sessions & 16.0 \\
Live whiteboard & 17.6 \\
Virtual group conferences & 8.6 \\
Other & 15.6 \\
\hline
\end{tabular}

This isolation effect is not new to adaptive systems, and in fact, is an issue in many fully online courses where effective pedagogical course design becomes a critical element. While students learn the content through immersion in the Realizeit platform, features of the learning management system can be utilized to provide additional resources for faculty to develop course scaffolding to create the most effective and interactive online environment to support student learning. However, given the results of this study where success rates were remarkably high, combined with the independent nature of the course modules and the knowledge-comprehension level of this course material, the learning benefit of interaction might come into question. This does seem at odds with current digital learning theory. However, knowledge acquisition in a go-at-your-own-pace environment may minimize the necessity of peer-to-peer interaction. Further research on these issues is necessary, especially for courses that require skills such as evaluation, analysis, synthesis, group problem solving, discovery learning and critical thinking.

With a system such as Realizeit, objective and node granularity is a critical component of the course design. Adaptive learning is driven by a decision engine that requires prior information in order to determine an optimal learning path for students. In order to do this effectively it needs adequate metaphoric degrees 
of freedom in order to "have room to operate." Modules with too few associated nodes can paralyze the system with respect to making accurate decisions. Too many nodes can overburden students with a daunting set of tasks. Although design is a critical component of any effective course, this becomes particularly important with true adaptive leaning, particularly those open, content-agnostic systems which allow faculty control over course design. The high front-end load in creating a course can pay immeasurable dividends in the student learning cycle. Adaptive learning demands the Goldilocks instructional design principle. The porridge cannot be too hot or too cold-it must just right. Adaptive courses cannot be too coarse or too granular. Classes must be designed at level of indenture that allows students to effectively manage their own learning with the support of a system.

Adaptive learning resonates with educational theories contending that students must be allocated the time needed to master facts, concepts or constructs. Additionally, it responds to the well understood principle that prior learning is necessary for the attainment of successively higher levels of achievement. Incorporating these two principles into learning design, although seemingly straightforward, represents a seismic shift in the traditional educational arrangement. Currently, courses are designed by incorporating certain constraints, even in the online environment. Semesters are sixteen weeks long. The final examination is administered during a specified time or time period. Assignments have due dates. The course ends. Grades are due by a specified date. These constraints are the means by which we manage the educational enterprise for students and instructors at the present time in higher education. However, most of these requirements can be loosened or eliminated in the adaptive learning environment. Theoretically, students can move at their own pace and are assessed for competence when they or the system deems they are ready. They can finish a course early or they can continue working after the semester ends. The implications of this thinking are substantial. Currently, if a student finishes a course early they might have to wait to take the exam at the end of the semester. If we are to embrace truly adaptive learning and gauge a true index of its effectiveness much of the current educational structure will require reconsideration.

Steven Johnson (2004) documents the influence of six phenomena in the world culture: clean, time, glass, light, cold and sound. The compelling aspects of these developments is that over decades and centuries they caused a profound change in the lives we lead today, but no one ever saw it coming. Forrester (1991) makes the case that:

1. We just cannot anticipate how an intervention will ripple through a complex system

2. Many outcomes will be counterintuitive

3. There will be positive and negative unanticipated side effects.

We speculate that should we stay the course with adaptive learning, we will encounter much of what Johnson and Forrester have demonstrated. The changes in our educational system will be profound but these changes, although potentially beneficial at many levels, may cause considerable angst and discomfort. In spite of that, adaptive learning can find its proper place in our transformed educational system. Johnson (2006) puts it this way: "History has its epic thresholds where the world is transformed in a matter of minutes - a leader is assassinated, a volcano erupts, a constitution is ratified. But there are other, smaller, turning points that are no less important. A hundred disparate historical trends converge on a single, modest act - some unknown person unscrews the handle of a pump on a street in a bustling city—and in the years and decades that follow, a thousand changes ripple out from that simple act. It's not that the world is changed instantly; the change itself takes many years to become visible. But the change is no less momentous for is quiet evolution” (162).

\section{Conclusions}

This small pilot study intended to answer fundamental questions about the impact of adaptive learning in higher education. Because this modality deviates considerably from traditional formats 
including face-to-face, online, blended, and lecture capture, understanding the way it impacts students, faculty members, and course structure becomes fundamentally important. The investigators sought to determine how students function in a learning environment where they experienced greatly increased learning latitude. Further, it was deemed important to discover what difficulties would be encountered as well what modifications might be necessary for this approach to be effective. In addition to gauging student responses, the study focused on how students engage and achieve, and what important subgroups might be identified from a predictive analytics perspective. How early can struggling students be identified? What outcome measures will be most informative for adaptive learning courses and how are traditionally accepted pedagogical assumptions challenged? However, as with many pilot studies, the questions addressed tend to raise additional issues and consequences.

Initial concerns about students being able to function in the Realizeit platform were mostly unfounded. Students experienced relatively few issues and made a seamless transition to this new platform. In fact, from their survey responses, UCF's concerns about preparing orientation and support materials may not have been necessary. At the underlying evaluation level, the latent trait analysis suggests that students evaluate their adaptive learning experience in much the same way that they do other course formatsdesign, delivery, learning facilitation, accurate assessment, understanding the rules of engagement and filtering out distraction and noise.

Given students' control over how, when, and for how long they approach learning, this modality appears to have been effective for a large majority-most of whom were successful. Many students completed the entirety of their assignments. The top performing students showed learning characteristics that were very similar to the class as a whole. A number of them took the opportunity to review and revise their work and some finished the course early. Others, however, had to be reminded of pending deadlines. In the second semester of the study the instructor opened the course and made it completely adaptive where students could address the modules in any order they preferred. Interestingly, however, the instructor reported the majority of students progressed through the material in the order in which it was described in the syllabus, essentially approaching their studies in a linear fashion. This leads the investigators to conclude that truly progressing to adaptive learning requires a period of adjustment and may take some time as well as a change in mindset.

Although a small number of students in this project did not succeed in the course, the learning outcomes measures (module scores, knowledge covered and knowledge state) provided evidence of the difficulty potential for those students very early in the course. The slope of the line for those measures from Module 1 to Module 2 turned out to be an excellent predictor of success. The investigators speculate that this approach has an embedded analytics component and that measures external to the course may not be necessary to predict those at risk. This appears to be an important consideration since a major issue in analytics involves designing effective interventions. However, in Realizeit the interventions are relatively straightforward. Students need to complete the modules and revise their work until they have achieved competency and, if needed, be given additional needed time. 


\section{References}

Anderson, R. D., \& Rubin, H. (1956). Statistical inference in factor analysis. Proceedings of the Third Berkeley Symposium of Mathematical Statistics and Probability, 5, 111-150.

Association of Public \& Land-Grant Universities. Personalizing Learning with Adaptive Courseware. Retrieved from http://www.aplu.org/projects-and-initiatives/personalized-learningconsortium/plc-projects/plc-adaptive-courseware/

Bates, M. J. (1989). The design of browsing and berrypicking techniques for the online search interface. Online Information Review, 13(5), 407-424. Retrieved from http://comminfo.rutgers.edu/ tefko/Courses/e530/Readings/Bates_Berrypicking.pdf

Bill \& Melinda Gates Foundation. (2014, November). Early progress: Interim research on personalized learning. Retrieved from http://collegeready.gatesfoundation.org/wpcontent/uploads/2015/06/Early-Progress-on-Personalized-Learning-Full-Report.pdf

Bowker, G. C., \& Star, S. L. (2000). Sorting things out: Classification and its consequences. Cambridge, MA: The MIT Press.

Boyd, d. (2014). It's complicated: The social lives of networked teens. Yale University Press.

Brown, J. (2015). Personalizing Post-Secondary Education: An Overview of Adaptive Learning Solutions for Higher Education. Retrieved from http://www.sr.ithaka.org/wpcontent/uploads/2015/08/SR_Report_Personalizing_Post_Secondary_Education_31815_0.pdf

Carpman, J. R., \& Grant, M. A. (2012). Directional sense: How to find your way around. Boston, MA: Institute for Human Centered Design.

Carroll, J. B. (1963). A model of school learning. Teachers College Record, 64, 723-733.

Cronbach, L. J. (1951). Coefficient alpha and the internal structure of tests. Psychometrika, 16(3), 297334. Retrieved from http://psych.colorado.edu/ carey/courses/psyc5112/readings/alpha_cronbach.pdf

de Ayala, R. J. (2009). The theory and practice of item response theory. New York, NY: The Guilford Press.

DeMars, C. (2010). Item response theory: Understanding statistics measurement. New York, NY: Oxford University Press, Inc.

Diamond, J. M. (1997). Guns, germs, and steel. New York, NY: W.W. Norton \& Company, Inc.

Dziuban, C. D., \& Shirkey, E. C. (1974). When is a correlation matrix appropriate for factor analysis? Some decision rules. Psychological Bulletin, 81(6), 358. doi: 10.1037/h0036316

Dziuban, C. D., \& Shirkey, E. C. (1993, November). S.D. 50 -A sequential psychometric criterion for the number of common factors. Presented at the Annual Conference for Florida Educational Research Association, Destin, Florida. 
Forrester, J. W. (1991). System dynamics and the lessons of 35 years. In K. B. D. Greene (Ed.), Systems-based approach to policymaking. Norwall, MA: Kluwer Academic.

Hall, S. S. (2004). I, Mercator. In K. Harman (Ed.), You are here: Personal geographies and other maps of the imagination (pp. 15-19). New York, NY: Princeton Architectural Press.

Hartigan, J. A., \& Wong, M. A. (1979). Algorithm AS 136: A K-Means Clustering Algorithm. Journal of the Royal Statistical Society. Series C (applied Statistics), 28(1), 100-108. http://doi.org/10.2307/2346830

Hill, B. D. (2011). The sequential Kaiser-Meyer-Olkin procedure as an alternative for determining the number of factors in common-factor analysis: A Monte Carlo simulation (Doctoral dissertation, Oklahoma State University). Retrieved from http://login.ezproxy.net.ucf.edu/login?url=http://search.proquest.com/docview/898980750?accou ntid $=10003$

Hedges, L. V. (1981). Distribution theory for Glass's estimator of effect size and related estimators. Journal of Educational Statistics, 6, 107-128. doi:10.3102/10769986006002107

Hendrickson, A. E., \& White, P. O. (1964). Promax: A quick method for rotation to oblique simple structure. British Journal of Statistical Psychology, 17(1), 65-70. Retrieved from http://onlinelibrary.wiley.com/doi/10.1111/j.2044-8317.1964.tb00244.x/pdf

Howlin, C., \& Lynch, D. (2014). A framework for the delivery of personalized adaptive content. Web and Open Access to Learning (ICWOAL), 2014 International Conference on, Dubai, pp. 1-5. doi: 10.1109/ICWOAL.2014.7009203

Illich, I. (1972). Deschooling Society. London, England: Marion Boyars.

Johnson, S. (2004). How we got to now: Six innovations that made the modern world. New York: Riverhead.

Johnson, S. (2006). The ghost map: The story of London's most terrifying epidemic, and how it changed science, cities, and the modern world. New York: Riverhead.

Johnson, S. (2010). Where good ideas come from: The natural history of innovation. New York, NY: Riverhead Books.

Kaiser, H. F., \& Rice, J. (1974). Little Jiffy, Mark IV. Educational and Psychological Measurement, 34, 111-117.

Lazarsfeld, P. F. (1995). Recent developments in latent structure analysis. Sociometry and the Science of Man, 18(4), 391-403).

Levitt, S. D., \& Dubner, S. J. (2014). Think like a freak. New York, NY: HarperCollins.

Levy, J. C. (2013). Adaptive learning and the human condition. Upper Saddle River, NJ: Person Education, Inc.

Lord, F. M., \& Novick, M. R. (2008). Statistical theories of mental test scores. USA: Information Age Publishing Inc. 
National Council of State Board of Nursing. (2016). Retrieved from https://www.ncsbn.org/index.htm

National DETA Research Center. (2014, November 20). DETA grant summary. Retrieved from http://uwm.edu/deta/grant-summary/

Morville, P. (2005). Ambient findability: What we find changes who we become. Sebastopol, CA: O’Reilly Media, Inc.

Mulaik, S.A. (2009). The foundations of factor analysis, second edition. London, United Kingdom: Chapman and Hall.

Online Learning Consortium. Digital Learning Innovation Award. Retrieved from http://onlinelearningconsortium.org/about/digital-learning-innovation-award/

Pacheco, E. (2014, October 14). Online Learning Consortium awarded adaptive learning grant. Retrieved from: http://onlinelearningconsortium.org/news_item/online-learning-consortiumawarded-adaptive-learning-grant/

Rasch, G. (1998, September). A mathematical theory of objectivity and its consequences for model construction. European Meeting on Statistics, Economics and Management Science.

Schulz, K. (2010). Being wrong: Adventures in the margin of error. New York, NY: HarperCollins.

Senge, P. M., \& Roth, G. (1999). The dance of change: The challenges to sustaining momentum in a learning organization (the fifth discipline). New York, NY: Doubleday.

Silver, N. (2012). The signal and the noise: Why so many predictions fail—but some don't. New York, NY: The Penguin Press.

Turchi, P. (2009). Maps of the imagination: The writer as cartographer. San Antonio, TX: Trinity University Press.

Tyton Partners. (2013). Learning to Adapt: A Case for Accelerating Adaptive Learning in Higher Education. Retrieved from http://tytonpartners.com/tyton-wp/wpcontent/uploads/2015/01/Learning-to-Adapt_Case-for-Accelerating-AL-in-Higher-Ed.pdf

Tyton Partners. (2016). Learning to Adapt 2.0: The Evolution of Adaptive Learning in Higher Education. Retrieved from http://tytonpartners.com/tyton-wp/wp-content/uploads/2016/04/Tyton-PartnersLearning-to-Adapt-2.0-FINAL.pdf

Zmuda, A., Curtis, G., \& Ullman, D. (2015). Learning personalized: The evolution of the contemporary classroom. San Francisco, CA: John Wiley \& Sons, Inc. 